Rodríguez, C., Aroca, A. \& Rodríguez, F. M. (2019). Procesos de medición en una práctica artesanal del caribe colombiano. Un estudio desde la Etnomatemática. Revista Latinoamericana de Etnomatemática, 12(4), 41-68. DOI: 10.22267/relatem.19124.36

Artículo recibido el 13 de marzo de 2019. Aceptado para publicación el 3 de diciembre del 2019

\title{
Procesos de medición en una práctica artesanal del caribe colombiano. Un estudio desde la Etnomatemática
}

\section{Measurement processes in an artisan practice of the colombian caribbean. A study from Ethnomathematics}

\author{
Camilo Andrés Rodríguez-Nieto ${ }^{1}$ \\ Armando Aroca Araújo ${ }^{2}$ \\ Flor Monserrat Rodríguez-Vásquez ${ }^{3}$
}

\begin{abstract}
Resumen
En esta investigación se identificó que se le está prestando escasa atención a las formas de medir, contar, entre otras actividades que hacen grupos culturales en sus prácticas artesanales, especialmente en procesos relacionados con la gastronomía, lo cual podría contribuir a la enseñanza y aprendizaje de los sistemas de medidas o métricos. Por tal razón, en este artículo se caracterizan los aspectos matemáticos involucrados en los procesos de medición de un comerciante de bollo de yuca residente en Sibarco, Colombia. Teóricamente el trabajo se fundamentó en el programa Etnomatemática y en las acepciones de medir, medida, unidad de medida y bollo. La metodología usada fue de tipo cualitativa-etnográfica. Para recolectar la información, se utilizó la entrevista semiestructurada, se grabaron audios, se tomaron notas de campo y se videograbó. Los resultados muestran que el comerciante de bollo de yuca realiza procesos de medición usando unidades de medidas no convencionales y convencionales como la braza, la carga, el bulto, el lao, el tercio, balde, tanque y el litro, libra, onza, horas. Asimismo, se identificaron equivalencias entre unidades de medida en la práctica. Se considera que los resultados pueden aportar a la enseñanza y aprendizaje de las matemáticas, dado que las unidades de medidas reportadas son un material que les permitiría a los profesores de matemáticas crear situaciones contextualizadas que vinculen al estudiante con su entorno sociocultural próximo.
\end{abstract}

Palabras clave: Procesos de medición; Equivalencias; Conversiones; Práctica artesanal; Programa Etnomatemática.

\begin{abstract}
\footnotetext{
${ }^{1}$ Licenciado en Matemáticas por la Universidad del Atlántico (UA), Colombia. Magister en Ciencias Área: Matemática Educativa por la Universidad Autónoma de Guerrero (UAGro), México. Candidato a Doctor en Ciencias con Especialidad en Matemática Educativa en la UAGro, México. Integrante del Grupo de Investigación Horizontes en Educación Matemática (GIHEM). E-mail: crodriguez@uagro.mx; Orcid: https://orcid.org/0000-0001-9922-4079

${ }^{2}$ Candidato a doctor en Educación énfasis Educación Matemática - Universidad Distrital Francisco José de Caldas. Profesor Asociado Universidad del Atlántico, Barranquilla, Colombia. Líder Grupo de Investigación Horizontes en Educación Matemática (GIHEM). Email: armandoaroca@mail.uniatlantico.edu.co; Orcid: http://orcid.org/0000-0003-2786-4848

${ }^{3}$ Doctora en Educación Matemática por la Universidad de Salamanca, España. Coordinadora de la Maestría en Ciencia Área: Matemática Educativa en la Universidad Autónoma de Guerrero, México (UAGro). University of Guerrero (UAGro), Mexico. Av. Lázaro Cárdenas S/N, Ciudad Universitaria, CP. 39087, Chilpancingo Guerrero, Mexico. E-mail: flor.rodriguez@uagro.mx; Orcid: https:// orcid.org/0000-00029596-4253
} 
In this research it was identified that little attention is being paid to the ways of measuring, counting, among other activities that cultural groups do in their artisan practices, especially in processes related to gastronomy, which could contribute to the teaching and learning of measurement or metric systems. For this reason, this article characterizes the mathematical aspects involved in the measurement processes of a cassava bun merchant residing in Sibarco, Colombia. Theoretically, the work was based on the Ethnomathematics program and on the meanings of measuring, measurement, unit of measurement and bun. The methodology used was of a qualitative-ethnographic type. To collect the information, the semistructured interview was used, audios were recorded, field notes were taken and video was recorded. The results show that the cassava bun dealer performs measurement processes using unconventional and conventional units of measurement such as breaststroke, load, bulk, lao, tercio, bucket, tank, and liter, pound, ounce, hours. Likewise, equivalences were identified between measurement units in practice. The results are considered to contribute to the teaching and learning of mathematics, since the reported units of measurement are a material that would allow mathematics teachers to create contextualized situations that link the student with his or her close sociocultural environment.

Keywords: Measurement processes; Equivalences; Conversions; Artisan practice; Ethnomathematics Program.

\section{INTRODUCCIÓN}

La actividad de medir es fundamental en el diario vivir de las personas y centra su utilidad en la comparación de unidades de medidas con magnitudes como la longitud, superficie, tiempo, masa, capacidad, entre otras. También, el hombre ha desarrollado sistemas de conocimientos dependiendo de su entorno, considerando diferentes maneras de observar, comparar, clasificar, evaluar, cuantificar, medir, contar, representar e inferir a lo cual se le debería llamar etnomatemática (D’Ambrosio, 2016). Para Kula (1980) el mundo fue cortado a la medida del hombre, de tal forma que, en principio medía los objetos con las partes de su cuerpo (brazo, pie, mano, entre otros), razón por la cual algunas comunidades utilizan unidades de medidas no convencionales para medir en sus labores cotidianas. En este contexto, el Ministerio de Educación Nacional de Colombia [MEN] (2006) reconoce que:

Históricamente, el pensamiento métrico se perfeccionó con el refinamiento de las unidades de medida de longitud, tomadas al comienzo de partes del cuerpo y por tanto muy diversas en cada región y cultura, que fueron luego estandarizadas para el comercio y la industria (p. 63).

Asimismo, medir es una actividad que se manifiesta de manera diferente teniendo en cuenta el contexto donde se encuentren las personas, debido a que cada pueblo desarrolla su propia matemática y su sistema de medida (Gerdes, 2013). Algunas investigaciones sobre etnomatemática han reportado unidades de medidas no convencionales similares como la braza, pero el contexto de uso es totalmente diferente (Berrío, 2009; Chieus, 2009; Rey y Aroca, 2011; Aroca, 2012; Carabalí, 2012; Soza y Dávila, 2012; Oliveira 
Rodríguez, C., Aroca, A. \& Rodríguez, F. M. (2019). Procesos de medición en una práctica artesanal del caribe colombiano. Un estudio desde la Etnomatemática. Revista Latinoamericana de Etnomatemática, 12(4), 41-68. DOI: 10.22267/relatem.19124.36

Júnior y Mendes dos Santos, 2016; Trujillo, Miranda y De la Hoz, 2018; Rodríguez-Nieto, Mosquera y Aroca, 2019).

Es oportuno mencionar que, en la revisión de la literatura se observaron varias investigaciones centradas en identificar las formas de medir, medidas de capacidad volumétrica no convencionales (Blanco-Álvarez, Fernández-Oliveras y Oliveras, 2017), medidas no convencionales de longitud (Chieus, 2009; Rey y Aroca, 2011; Oliveira Júnior y Mendes dos Santos, 2016; Aroca, 2008; 2012; 2018a), medidas en el diseño de sombreros (Enríquez, Millán y Aroca, 2012), medidas en la elaboración de mochilas Ahruacas, donde utilizaban la puntada como unidad de medida (Aroca, 2008), medidas en los diseños rupestres de los hipogeos de Tierradentro (Aroca, 2013). En Aravena, Loncomilla y Pizarro (2020) se identificaron usos de unidades de medida como la tolerancia (no convencional), el metro, la pulgada y sus relaciones entre sí, en la elaboración de muebles en el sur de Chile.

Otras investigaciones muestran el uso de unidades de medidas no convencionales de capacidad, por ejemplo, el almud, la lata y el litro (Ávila, 2014), el litro, el cuartillo y la arpilla usados por comerciantes de un mercado mexicano (Rodríguez-Nieto, Morales, Muñoz y Navarro, 2017), el galón y el bulto usados por un albañil (Arias, Morales y Orjuela, 2010), el bulto equivalente a 70 kilos utilizado para empacar auyamas y mazorcas de maíz (Zambrano, 2012).

En la actualidad se siguen encontrando otras comunidades (comerciantes de bollos, pescadores, trabajadores de la madera, albañiles, tejedoras de mantas, canastos o mochilas, etc.) que emplean la matemática de manera diferente, especialmente cuando miden, combinan unidades de medida, establecen equivalencias y conversiones en su propia forma de medir y en su lenguaje para satisfacer sus necesidades en la cotidianidad. Por ejemplo, García-García y Bernandino-Silverio (2019) investigaron acerca de la elaboración y uso del güilile e identificaron el uso de la cuarta y evidenciaron partes de dicho artefacto con forma de circunferencia, parábola, paraboloide, rectas, entre otros.

En este artículo se muestran los resultados de una investigación sobre la Etnomatemática que se emplea en la elaboración del bollo de yuca ${ }^{4}$, actividad realizada en Sibarco,

\footnotetext{
${ }^{4}$ La yuca es un tubérculo conocido científicamente como Manihot esculenta Crantz, caracterizada por ser un alimento básico para los seres humanos, animales y es esencial para hacer productos como el almidón, dextrosa, harina, panes, alcohol, entre otros derivados (Knowles, Pabón y Carulla, 2012; Mera y Carrera, 2005; Meza y Julca, 2015; Suárez y Mederos, 2011). La taxonomía de la yuca está centrada en el "reino
} 
corregimiento agrícola del municipio de Baranoa, situado en el departamento del Atlántico, Colombia. Es importante investigar esta práctica artesanal porque en la mayoría de los estudios fundamentados en el Programa Etnomatemática poco se ha explorado la matemática inmersa en la gastronomía, donde se siguen procedimientos para la obtención de un producto alimenticio (en este caso, el bollo de yuca). Además, en el caribe colombiano, el bollo de yuca es conocido como un alimento ancestral acompañante de comidas típicas como la sopa de guandú, butifarra, queso, carne asada, pescado frito, entre otros, pero es visto generalmente con fines comerciales y no como una práctica artesanal que involucra la matemática vinculada al proceso de elaboración del bollo de yuca, que implícitamente puede contribuir al sector educativo, en especial al proceso de enseñanza y aprendizaje de las matemáticas escolares.

Además, existe una subvaloración en el sector educativo y en los procesos de enseñanza de aquellos sistemas métricos que incluyen unidades de medida no convencionales (e.g., cuarta, jeme, braza, entre otras), que están al alcance de los estudiantes y profesores, pero este último considera más el uso del sistema internacional o estandarizado (Mosquera, Rodríguez-Nieto y Suárez, 2015). Por tal motivo, esta investigación tuvo como propósito, caracterizar los aspectos matemáticos involucrados en los procesos de medición de un comerciante de bollo de yuca residente en Sibarco. En este contexto, Shirley y Palhares (2016) mencionan que, "a menudo se ha señalado que los ejemplos etnomatemáticos demuestran nuevas formas de ver las matemáticas y conducen a una mejor comprensión de los conceptos, procedimientos y usos del contenido curricular" (p. 13-14).

El MEN (2006) propone que, se deben promover aspectos como la comprensión de conservación de magnitudes, seleccionar unidades de medida, patrones y de instrumentos y procesos de medición, entre otros. Asimismo, compartimos la perspectiva de Rosa y Lawrence (2016) cuando afirmaron que, "los estudios detallados de las ideas y prácticas matemáticas de distintos grupos culturales ciertamente nos permiten ampliar nuestra comprensión de la lógica interna y las ideas matemáticas de diversos grupos de estudiantes" (p.2).

vegetal, División Spermatophyta, Subdivisión Angiospermae y a la Case Dicotiledoneae. Se encuentra ubicada en el Orden Euphorbiaceae, Tribu Manihotae a la que pertenece el género Manihot" (Suárez y Mederos, 2011, p.27). 
Rodríguez, C., Aroca, A. \& Rodríguez, F. M. (2019). Procesos de medición en una práctica artesanal del caribe colombiano. Un estudio desde la Etnomatemática. Revista Latinoamericana de Etnomatemática, 12(4), 41-68. DOI: 10.22267/relatem.19124.36

\section{ELEMENTOS TEÓRICOS}

En este apartado se presenta la conceptualización de etnomatemática, las acepciones de medir, medida, unidad de medida, medición, y, por último, se define y caracteriza el término: bollo de yuca.

\subsection{Etnomatemática}

En esta investigación se reconoce que, "la Etnomatemática como campo se estableció en la década de 1970. En ese momento, introdujo una nueva perspectiva en la educación matemática, considerándola en relación con las fuerzas culturales, políticas, sociales y económicas que dan forma al mundo" (D’Ambrosio y Knijnik, 2020, p. 283). También, se ha denominado Programa Etnomatemática y es conocido por estudiar y valorar:

El conjunto de modos, estilos, artes y técnicas (technés o ticas) para explicar, aprender, conocer, lidear en/con (matemá) los ambientes naturales, sociales, culturales e imaginarios (etnos) de una cultura, o sea, Etnomatemática son las ticas de matemá en un determinado etno (D’Ambrosio, 2014, p.103).

Aunque Aroca (2016) manifiesta que, considerar la etimología de la Etnomatemática como las tic de la de mathema en una etno, podría obstaculizar la interpretación y representación del conocimiento matemático de una persona incluso considera que dicha secuencia es un reduccionismo de lo que se considera conocer el pensamiento matemático de un persona o el saber matemático de una comunidad, una alternativa es pensar sobre una etnografía matemática propuesta en Aroca (2018), lo cual no expondremos en este artículo. Por lo tanto, la Etnomatemática:

No sólo es lo sociocultural, también es lo histórico, lo político, lo ético, su relación con la educación, la formación, la pedagogía, la didáctica, lo religioso, lo económico, lo psicológico, lo lingüístico que median en la enseñanza y aprendizaje de las matemáticas, y no a todas estas dimensiones las podemos interpretar mediante las tics de mathema en una etno (Aroca, 2016, p.192).

En concordancia con la visión integradora e inclusiva de Aroca (2016), se comparte la perspectiva de D'Ambrosio y Knijnik (2020) quienes sostienen que, el programa Etnomatemática se fundamenta conceptualmente en la antropología, la filosofía de las matemáticas y la historia. Además, desde su origen, "asumió que para crear nuevos 
conocimientos se requiere mirar a la sociedad en su conjunto y a sus dimensiones culturales constitucionales, teniendo en cuenta las tradiciones y expectativas de sus miembros" (p. 286). Además, la Etnomatemática también enfatiza en la importancia de las comunidades en relación con el ambiente escolar, debido a que conecta la matemática con las prácticas culturales desarrolladas y utilizadas localmente (Rosa y Orey, 2018, p.72). Sin embargo, "las formas de medir o de localizar propias de la comunidad de referencia, así como los instrumentos de medición, en general juegan sólo el papel de motivación para aprender, o de elemento facilitador de la comprensión" (Ávila, 2014, p. 44).

\subsection{Medir, medida, unidad de medida y medición}

En el caso de esta investigación, el interés es conceptualizar sobre la práctica de medir. Medir es repetir una unidad de medida sobre la extensión de la magnitud, de tal manera que, el intervalo a medir quede cubierto en su totalidad (Dickson, Brown y Gibson, 1991). Medir es una "actividad universal e importante para el desarrollo de ideas matemáticas y se ocupa de comparar, ordenar y cuantificar cualidades que tienen valor e importancia" (Bishop, 1999, p. 55). Asimismo, "medir es comparar una cantidad con una estándar y expresar el resultado de la comparación por medio de un número" (São Paulo, 2012, p. 43).

Otro concepto clave de la investigación es el de unidad de medida. Para expresar lo que se entiende por unidad de medida se tomaron como referencia tres fuentes. Una de ellas es la enunciada por Kula (1980) quien afirma que, la creación de una medida requiere de una actividad mental compleja, basada en la elección abstracta de una de las características propias de unos objetos dados y la comparación de éstos en base a aquélla. Otra fuente es Godino, Batanero y Roa (2002) quienes mencionan que, la unidad de medida es la cantidad usada como elemento de comparación reiterada. Por último, se tiene como fuente la definición que se presenta en la tercera edición en español del Vocabulario Internacional de Metrología Conceptos fundamentales y generales, y términos asociados VIM (2012) que expresa como unidad de medida como la "magnitud escalar real, definida y adoptada por convenio, con la que se puede comparar cualquier otra magnitud de la misma naturaleza para expresar la relación entre ambas mediante un número". La práctica de medida de magnitudes según Alsina (2019), viene dada por el uso de: 
Rodríguez, C., Aroca, A. \& Rodríguez, F. M. (2019). Procesos de medición en una práctica artesanal del caribe colombiano. Un estudio desde la Etnomatemática. Revista Latinoamericana de Etnomatemática, 12(4), 41-68. DOI: 10.22267/relatem.19124.36

Instrumentos diversos y unidades de referencia para la cuantificación. Las unidades pueden ser antropométricas (cuando se usa el propio cuerpo para medir, como por ejemplo palmos en el caso de la medida de la longitud); no convencionales (cuando se usan objetos diversos que no han sido diseñados inicialmente para medir, como por ejemplo un palo en el caso de la medida de longitud); o bien estándares (cuando se usa un instrumento de medida indirecta que ha sido diseñado específicamente para medir, como por ejemplo una cinta métrica en el caso de la medida de longitud) (p. 6-7).

Ahora bien, desde la perspectiva de Godino et al. (2002), la medición inicia con la percepción que tiene una persona acerca de una magnitud que tiene la característica de ser medido, es decir, la medición es el proceso que "procede secuencialmente desde la percepción a la comparación y después a la aplicación de un estándar de medida (o referente)" (p. 639). Bajo estas indicaciones conceptuales analizamos los datos encontrados en el trabajo de campo que más adelante se establecerá.

\subsection{El Bollo de yuca}

Desde el punto de vista de la Real Academia Española [RAE] (2018) un bollo es considerado como una pieza esponjosa hecha con masa de harina y agua y cocida al horno. Algunas investigaciones se han centrado en otros tipos de bollo, por ejemplo, el bollo de limpio (Álvarez, Denise De Paula y Durango, 2016), el bollo de maíz ejecutivo (Vega, Huguet y Peralta, 2015), pero solo mencionan que es un alimento que no tiene conservantes ni ingredientes perjudiciales para la salud. Mientras que, en esta investigación consideramos que un bollo es un alimento conformado a base de harina húmeda y cocido en agua con forma de elipsoide desde una perspectiva de la Geometría espacial. En particular, el bollo de yuca es un alimento ancestral derivado de la yuca (Manihot esculenta Crantz), que está constituido por una masa de yuca rallada, simple, sin almidón, macizo, cubierto con hoja de maíz, amarrado con pita de saco y tiene forma elipsoidal (ver Figura 1). Se caracteriza por ser uno de los alimentos típicos de la cultura de Sibarco proveniente de la etnia Mokaná y de otros pueblos del departamento del Atlántico. Además, su comercialización se ha expandido por toda la región caribe colombiana. 


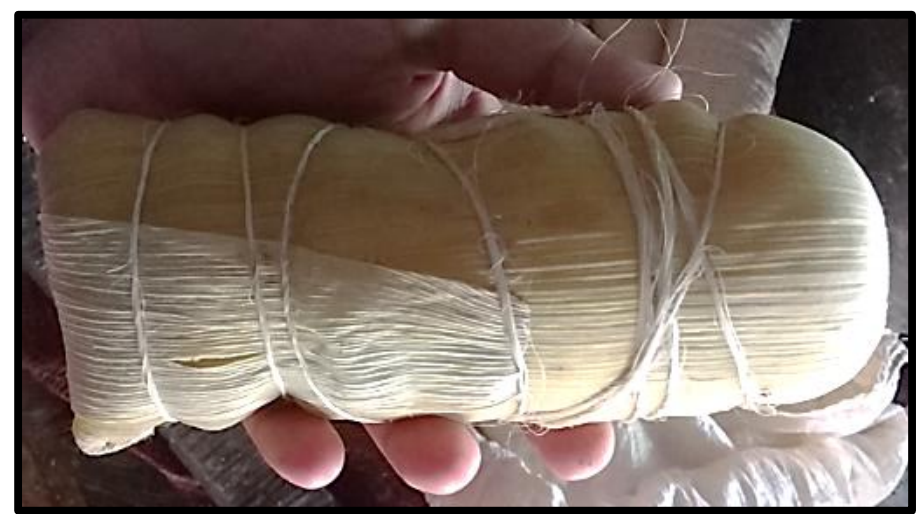

Figura 1. El bollo de yuca hecho en Sibarco, Atlántico, Colombia.

Fuente. Fotografía de los autores, trabajo de campo.

\section{METODOLOGÍA}

Esta investigación es de tipo cualitativa-descriptiva (Hernández, Fernández y Baptista, 2014; Vasilachis, 2006) desde una perspectiva etnográfica ${ }^{5}$ basada en la observación participante (Ameigeiras, 2006; Goetz y LeCompte, 1988), centrada en estudiar y describir las formas de medir de un comerciante en el proceso de elaboración de bollos de yuca en el corregimiento de Sibarco. La investigación se desarrolló en cuatro etapas, 1) familiarización con el comerciante (participante), 2) observación participante para conocer la práctica del bollo de yuca donde se realizaron entrevistas semiestructuras. 3) análisis de los datos obtenidos de las entrevistas, y, por último, 4) validación de la información obtenida. D'Ambrosio y Knijnik (2020) afirman que, "la mayor parte de la investigación en etnomatemática implica llevar a cabo un trabajo de campo en el que se utilizan técnicas etnográficas, como la observación participante, la grabación de audio, el diario de campo y la entrevista" (p. 285).

En la primera etapa de familiarización ${ }^{6}$ se visitó al comerciante de bollos de yuca con el propósito de aprender sobre su práctica y pedirle el permiso a él para entrevistarlo. En esta etapa se hizo una entrevista semi estructurada con el propósito de conocer a Jesús, uno de los comerciantes de bollos del corregimiento de Sibarco, el más reconocido y destacado por abastecer las tiendas y vender su producto en el mercado público del

\footnotetext{
${ }^{5}$ La etnografía hace referencia a la descripción de una cultura, comprender el estilo de vida de las personas que conforman un grupo, por medio de la observación participante, dando la oportunidad de ver e interactuar con la finalidad de captar el significado de las acciones y los sucesos que ocurren en una práctica cultural (Spradley, 1979; Ameigeiras, 2006).

${ }^{6} \mathrm{El}$ investigador comprende la forma de cómo el grupo o persona experimenta, define y significa su realidad personal, interpersonal o cultural en el contexto de la vida cotidiana traduciéndolo en unas formas de pensar actuar y sentir idiosincráticas o características, para poder hacer preguntas respecto del tópico o problema de estudio (Sandoval, 2002).
} 
Rodríguez, C., Aroca, A. \& Rodríguez, F. M. (2019). Procesos de medición en una práctica artesanal del caribe colombiano. Un estudio desde la Etnomatemática. Revista Latinoamericana de Etnomatemática, 12(4), 41-68. DOI: 10.22267/relatem.19124.36

municipio de Baranoa, Atlántico, $\mathrm{y}$, por tal motivo fue seleccionado para esta investigación. En la Tabla 1, se presenta la información biográfica de Jesús.

\begin{tabular}{|c|c|c|c|c|}
\hline Participante & Edad & $\begin{array}{c}\text { Nivel de } \\
\text { escolaridad }\end{array}$ & $\begin{array}{c}\text { Años de } \\
\text { experiencia en } \\
\text { la práctica } \\
\text { artesanal } \\
\end{array}$ & $\begin{array}{l}\text { Motivo por el cual hace } y \\
\text { vende bollos }\end{array}$ \\
\hline Jesús & $\begin{array}{c}61 \\
\text { años. }\end{array}$ & $\begin{array}{c}\text { Hasta } \\
\text { segundo año } \\
\text { de primaria. } \\
\text { (Sistema } \\
\text { educativo de } \\
\text { Colombia). }\end{array}$ & Más de 25 años. & $\begin{array}{l}\text { Jesús y su esposa comercializan } \\
\text { bollos de yuca para el sustento } \\
\text { diario de su familia y con esta } \\
\text { venta han logrado darles estudios } \\
\text { a sus cuatro hijos, quienes } \\
\text { actualmente son graduados de } \\
\text { bachiller. }\end{array}$ \\
\hline
\end{tabular}

Tabla 1. Datos biográficos básicos de un comerciante de bollos de yuca.

Fuente. Autores.

Posteriormente, en la segunda etapa se realizó una observación participante durante quince días en el lugar donde fabrican los bollos de yuca (Casa de Jesús). Para la recolección de la información se emplearon entrevistas semiestructuradas (Hernández et al., 2014), notas de campo y se consideraron cámaras videograbadoras. El trabajo de campo se hizo desde la obtención de la yuca (materia prima) hasta conseguir el producto final (bollo de yuca).

En la tercera etapa se analizaron los datos, teniendo en cuenta las transcripciones de los audios y videos. Este análisis estuvo regido mediante el principio metodológico que le interpretamos a D'Ambrosio (2014) y D'Ambrosio y Knijnik (2020): en las investigaciones basadas en el Programa Etnomatemática, donde se pueden observar las prácticas de diferentes grupos culturales, seguidas de un análisis de lo que hacen y por qué lo hacen. Además, se consideró la perspectiva de análisis de prácticas artesanales como se realizó en Rodríguez-Nieto et al. (2019), ver sección 4.

Por último, los autores de este artículo presentaron las transcripciones de las entrevistas y un avance del artículo al comerciante Jesús, quien revisó y validó la información obtenida, afirmando que el proceso de elaboración del bollo de yuca estaba ordenado, explicado detalladamente y completo. Además, mencionó que generalmente la elaboración y estructura del bollo de yuca es similar para otros comerciantes de Sibarco.

\section{ANÁLISIS Y RESULTADOS}


Los procesos de medición evidenciados en la elaboración del bollo de yuca se describen a continuación, haciendo uso de las transcripciones en forma de texto tomando en consideración las grabaciones de las entrevistas realizadas al comerciante, fotografías y notas de campo. Las etiquetas: Investigador (I), Participante (P), fueron tenidas en cuenta para los pasajes de audios.

Previo a la elaboración del bollo, es pertinente mencionar que el comerciante consigue la yuca en la finca donde es arrancada con la ayuda de un campesino. Luego, las deposita en sacos (bultos, laos), y por último los transporta en un burro hasta llegar a la casa. Para la elaboración del bollo, en un primer momento se pela y se lava la yuca. Este proceso se lleva a cabo en una hora aproximadamente por cada carga de yuca.

En la arrancada de la yuca y en el primer momento se evidencian algunas formas de medir por parte del comerciante cuando utiliza los sacos para empacar la yuca. En el siguiente pasaje de entrevista se presenta la información suministrada por el comerciante acerca las unidades de medida como la carga, los bultos, la cantidad de libras de yuca que contienen los bultos y su respectivo valor en pesos.

I. ¿Cómo es la cuestión de los sacos y la carga?

P. La carga de yuca son dos sacos y por los menos vale cincuenta mil pesos, está costando veinticinco mil un bulto.

I. ¿Cómo? ¿Un bulto es igual a un saco?

P. Si un bulto es igual a un saco y una carga son dos bultos.

I. Por ejemplo, una carga de yuca tiene...

P. Una carga de yuca, un saco está pesando ciento veinte libras.

I. Aja, y ¿Cómo calculan esas libras?

P. Cuando te está dando ochenta bollos.

La información proporcionada por el comerciante Jesús, se podría expresar de la siguiente manera:

$$
\begin{gathered}
1 \text { carga de yuca }=2 \text { sacos de yuca } \\
1 \text { bulto de yuca }=1 \text { saco de yuca } \\
1 \text { carga de yuca }=2 \text { bultos o sacos de yuca } \\
\frac{1}{2} \text { carga de yuca }=1 \text { saco o bulto de yuca } \\
1 \text { bulto o saco de yuca }=120 \text { libras } \\
\frac{1}{2} \text { carga de yuca }=120 \text { libras. } \\
1 \text { carga de yuca }=240 \text { libras. } \\
5 \text { cargas de yuca }=1.200 \text { libras. }
\end{gathered}
$$


Rodríguez, C., Aroca, A. \& Rodríguez, F. M. (2019). Procesos de medición en una práctica artesanal del caribe colombiano. Un estudio desde la Etnomatemática. Revista Latinoamericana de Etnomatemática, 12(4), 41-68. DOI: 10.22267/relatem.19124.36

La información anterior, permitió establecer relaciones entre la unidad de medida no convencional, su unidad equivalente, el peso de la carga de yuca y el precio de venta expresado en pesos como se evidencia en la Tabla 2.

\begin{tabular}{cccc}
\hline Unidad de medida & Equivalencia & Peso & Precio de venta \\
\hline $\begin{array}{c}1 \text { bulto de yuca } \\
1 \text { bulto o saco de } \\
\text { yuca }\end{array}$ & 1 saco & 120 libras & $\$ 25.000$ \\
1 carga de yuca & $\begin{array}{c}2 \text { la carga de yuca } \\
\text { 2 bultos o sacos }\end{array}$ & 120 libras & $\$ 25.000$ \\
\hline
\end{tabular}

Tabla 2. Equivalencias entre unidades de medidas no convencionales, peso y precio de venta.

Fuente. Autores, información obtenida del trabajo de campo.

Después de pelar la yuca, durante una hora éstas se lavan en una olla para quitarle algunos restos de la cáscara y dejarlas disponibles para el proceso de rallado. Una vez que se ha lavado la yuca, ésta es sometida a un proceso de rallado en una máquina (ralladora eléctrica), en un tiempo de una hora aproximadamente. El propósito de rallar es convertir la yuca en masa como se presenta en la Figura 2.

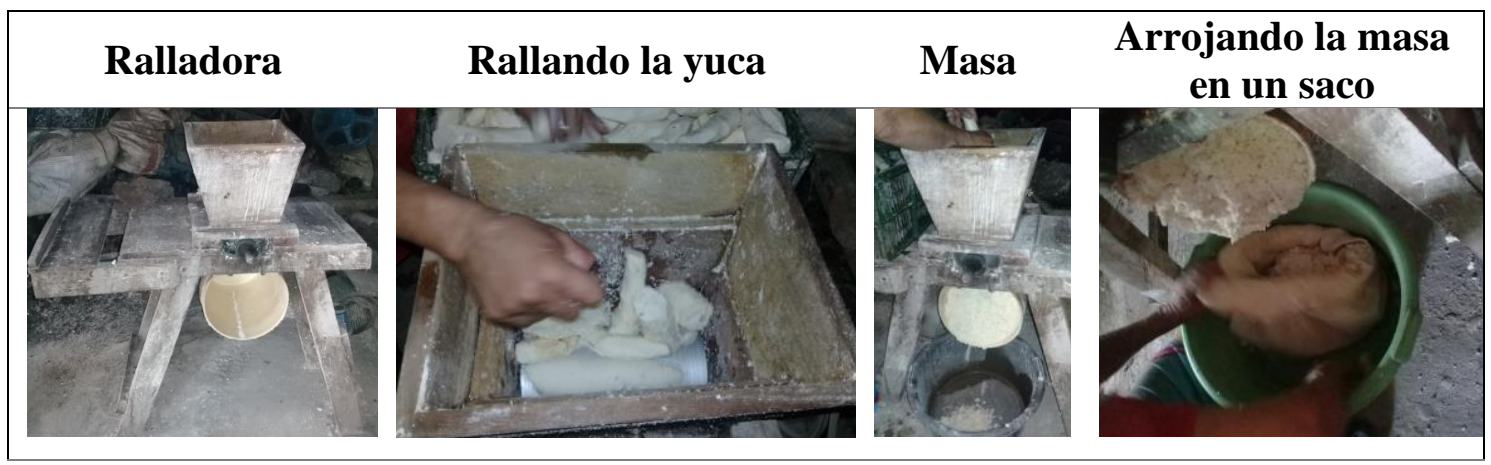

Figura 2. Rallado de la yuca.

Fuente. Fotografía de los autores, trabajo de campo.

La yuca al ser rallada y transformada en masa, se recoge en un saco y se le da otra rallada para que quede más fina. Cabe destacar que, en años anteriores se utilizaba un rayo de metal para rallar la yuca manual:

I. ¿Cuánto tiempo emplea rallando la yuca?

P. Una hora rallando, después de la rallada la exprimía.

Una vez que la masa se deposita en el saco no está acta para pelotear, por tal razón se exprime:

I. ¿Cuánto se demora exprimiendo?

P. Una hora exprimiendo, luego viene tres horas que es lo que se va a demorar peloteando, envolviendo y amarrando. 
La masa de yuca se recoge en el saco y se coloca encima de la batea, para seguir con el proceso de exprimir la masa durante una hora, caracterizado por dejar la masa sin agua o almidón y esté preparada para la limpieza y el peloteo, ver Figura 3.

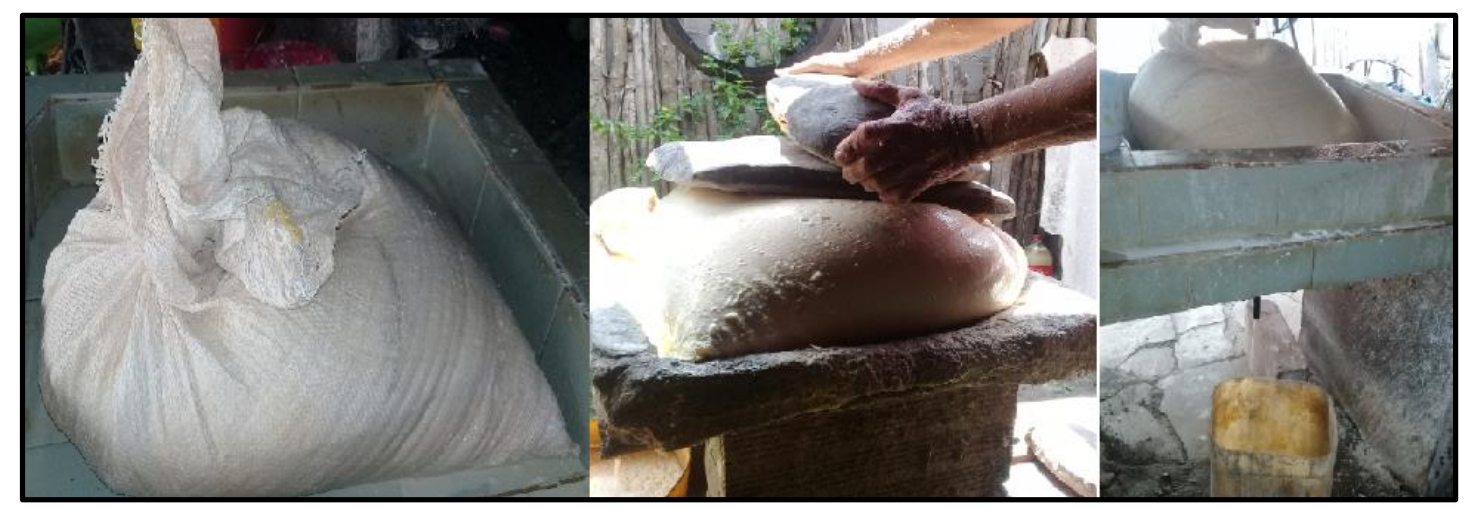

Figura 3. El comerciante coloca a exprimir la masa. Fuente. Fotografía de los autores, trabajo de campo.

En la Figura 3 se evidencia la forma de exprimir la masa por parte de Jesús, colocándole unas piedras con un peso de diez kilos sobre el saco para hacer presión para que destile el agua de yuca. Asimismo, se observa un tanque en la parte de abajo de la batea donde se concentra el agua de yuca útil para hacer el almidón o pegante derivado de la yuca. Seguidamente, se limpia o se espulga la masa, con la intención de quitarle algunos flecos que le quedan de la yuca, por su textura ver Figura 4.

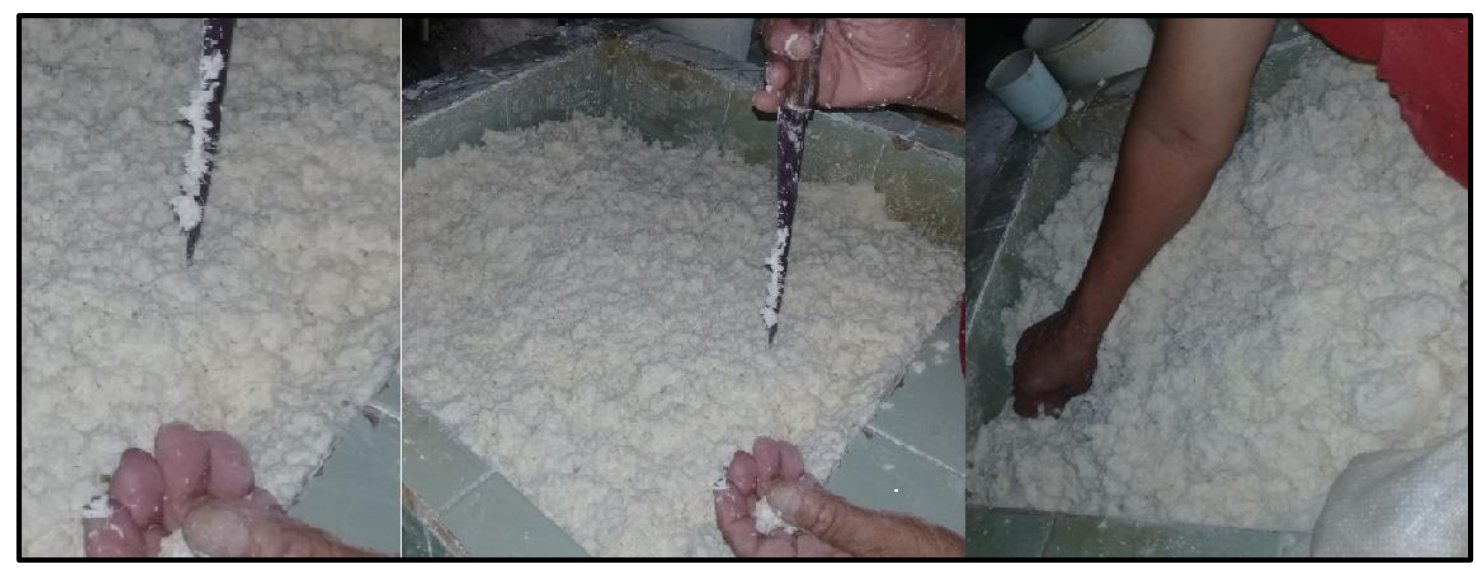

Figura 4. Limpieza o espulgue de la masa.

Fuente. Fotografía de los autores, trabajo de campo.

Cuando se llega a esta fase, es importante enfatizar en tres momentos: pelotear la masa, envolver la masa y amarrar la masa, ver Figura 5. 
Rodríguez, C., Aroca, A. \& Rodríguez, F. M. (2019). Procesos de medición en una práctica artesanal del caribe colombiano. Un estudio desde la Etnomatemática. Revista Latinoamericana de Etnomatemática, 12(4), 41-68. DOI: 10.22267/relatem.19124.36

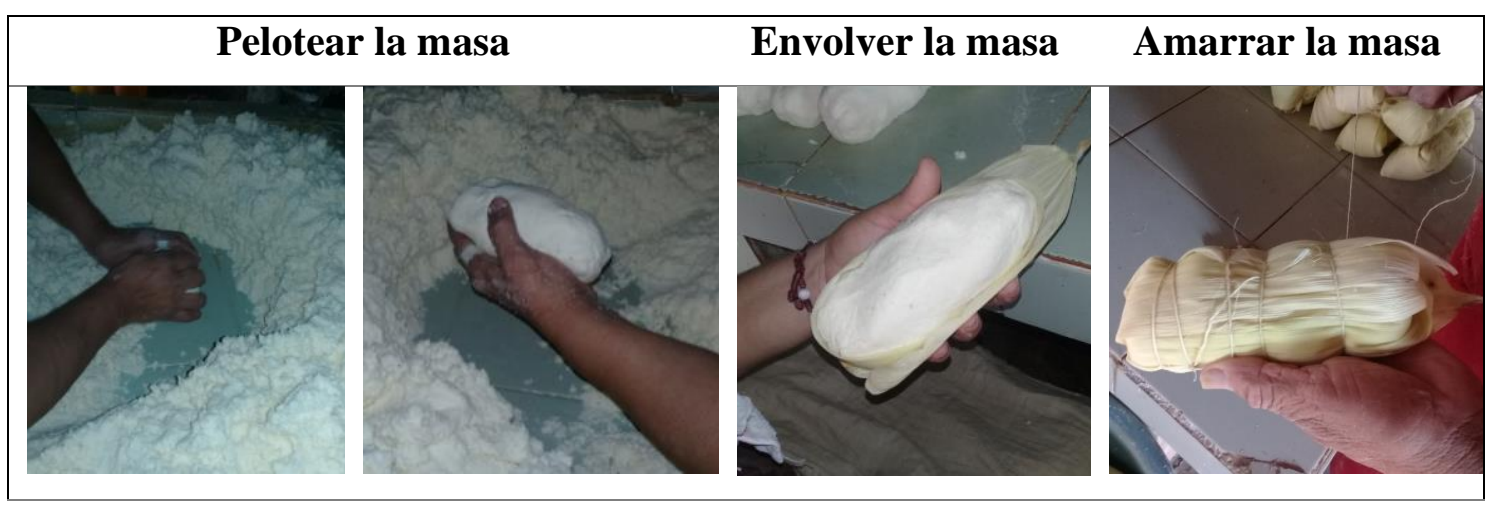

Figura 5. Proceso de peloteo, envoltura y amarre del bollo.

Fuente. Fotografía de los autores, trabajo de campo.

La masa se pelotea para darle forma de bollo redondo y alargado. A continuación, se presenta un pasaje de audio para evidenciar la información acerca del peloteo.

I. y ¿A qué se refiere con el término pelotear?

P. La señora pelotea, va cogiendo...

I. Pero ¿Qué es pelotear?

P. Pelotear es cuando uno coge la bolita e masa y va haciendo la forma del bollo.

I. ¿Pelotear es amasar?

P. Pelotéala claro, estrújala, como estruja un jugo de guanábana.

I. ¿Cuántas horas se lleva?

P. Ahí, nos echamos tres horas, desde ahí, desde que se pelotea hasta amárralo y échalo al fogón nos echamos dos, tres horas depende de la cantidad, si echa un saco no dura mucho, cuando hacemos dos tanques duramos más.

En el peloteo cuando la yuca está nueva cada unidad de masa (bollo) pesa una libra, y cuando la yuca tiene tiempo o está escaza el bollo pesa doce onzas, como se presenta en la siguiente expresión: 1 bollo $=1$ libra, para la yuca nueva; 1 bollo $=12$ onzas, para la yuca de hace tiempo o escasa. En este sentido, la expresión anterior se relaciona con la información referente al peso del bollo de yuca, la cual es comprobada con el siguiente pasaje de audio.

I. ¿Qué usa usted para identificar las libras?

P. No, ese más o menos es un cálculo que tiene uno aquí, ya sabe que el bollo va como de a libra.

I. Usted me decía algo respecto de cuando aumenta o disminuye el periodo de la yuca.

P. Disminuye el bollo, ya no sería de a libra sino de doce onzas.

I. ¿Cómo calculan? 
P. Se va disminuyendo, entonces uno pelotea un saco, joda salieron setenta bollos, hay que reducirle un poquito y va disminuyendo.

En un segundo momento se procede a la envoltura de la masa, donde se presentan tres etapas, corte de los culeros simétricos, forrar los extremos del bollo y forrar completamente el bollo. Envolver la masa se refiere a cubrir la masa con la hoja de maíz (tusa o cascaron), para que pueda conservar la forma dada el peloteo. En este proceso se utilizan dos tiras de tusa o culeros, útiles para que no se desarme el bollo, ver Figura 6.

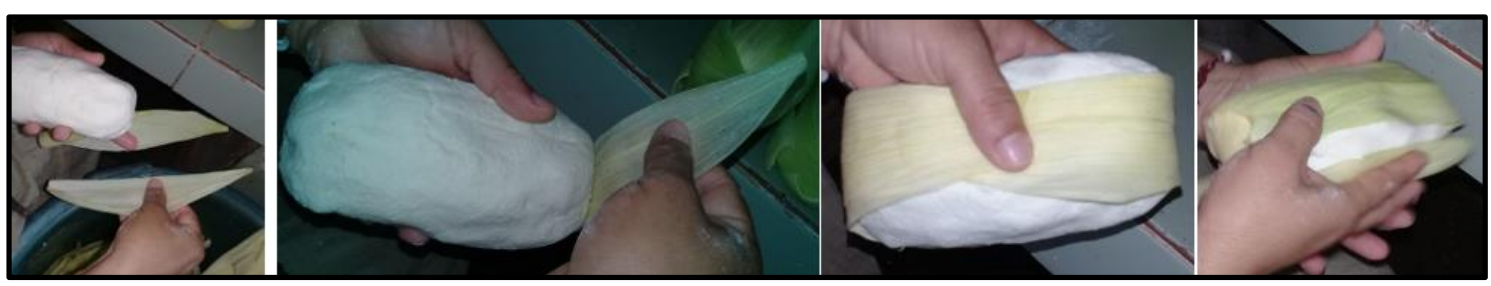

Figura 6. Función del culero en la envoltura del bollo.

Fuente. Fotografía de los autores, trabajo de campo.

A continuación, se presenta una transcripción de audio, donde se observa la explicación de Jesús acerca de la envoltura del bollo:

I. ¿Cómo les llaman a las dos tiras?

P. Esos se llaman culeros, son dos tusitas se parten y se le pone una a este lado y una a este lado.

I. Pero, ¿Esas tusas cómo deben ser, tienen una función?

P. Claro, en el tiempo de envolver, tiene uno que está poniéndolo para que el bollo no se enrice, no se suelte, no se dañe, por eso es que, si no lleva culero, se esmota (derramar la masa por los extremos) el bollo.

En el tercer momento se amarra el bollo para conservar la envoltura. Ello se logra sujetando las tusas a la masa, colocándoles una pita enrollada y apretada. En este proceso se utiliza una pita de saco que mide una braza, ver Figura 7.

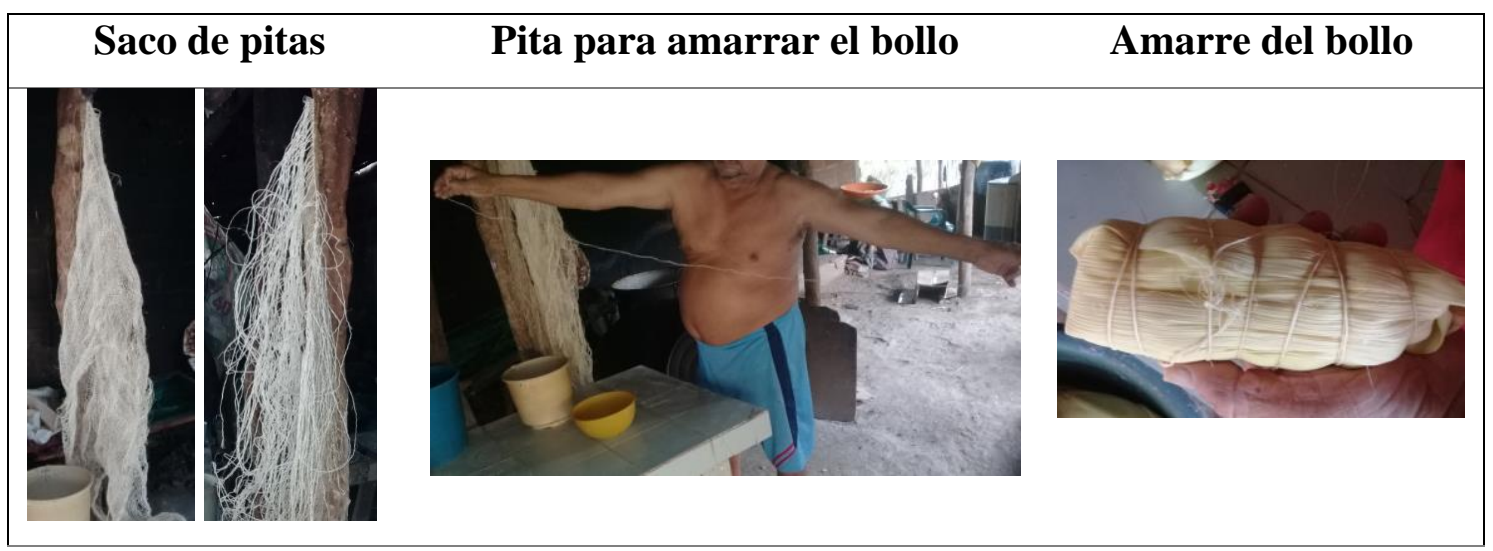

Figura 7. Amarre del bollo y medida de la pita. 
Rodríguez, C., Aroca, A. \& Rodríguez, F. M. (2019). Procesos de medición en una práctica artesanal del caribe colombiano. Un estudio desde la Etnomatemática. Revista Latinoamericana de Etnomatemática, 12(4), 41-68. DOI: 10.22267/relatem.19124.36

Fuente. Fotografía de los autores, trabajo de campo.

A partir del siguiente pasaje de audio se logró evidenciar cómo Jesús mide la pita utilizando la braza como una unidad de medida no convencional, afirmando que: 1 braza $\cong 2$ metros.

I. Usted dijo que una pita es igual a una braza.

P. Aja una braza viene siendo dos metros.

I. ¿Una braza tiene dos metros?

P. Tiene dos metros, mira esta es una braza, ahora verás...dos metros.

I. Para amarrar el bollo utiliza una...

P. Una pita de esta, cada bollo lleva una pita.

Además, otra de las unidades de medida no convencionales encontradas es la media braza, cuya longitud se mide (equivalencia) desde el pie hasta la altura del ombligo y es aproximadamente un metro, es decir, $\frac{1}{2}$ braza $\cong 1$ metro, como se muestra en el siguiente pasaje de audio.

I. ¿Ahí cuánto es?

P. Un metro hasta el ombligo.

Cabe destacar que, todas las pitas tienen el mismo largo, dos metros y salen de un saco de pitas.

I. Cuándo usted amarra ¿Cuántas vueltas lleva?

P. Pa' cogele, pa' ponele la pita, lleva cinco vueltecitas lleva el bollo.

I. Usted llega hasta la mitad, hace así chan, chan y voltea.

P. Pa' cogele.

I. Antes de voltearlo, ¿Cuántas vueltas le da?

P. Cuatro vueltas, uno, dos, tres, cuatro y cinco, aquí muere el bollo. Ya lleva una, dos aquí lleva la otra, tres, cuatro, entonces ahora uno coge y lo voltea, vuelve así y ya lo enrolla.

Posteriormente, en la Figura 8 Jesús dibujó el proceso de peloteo, envoltura y amarre del bollo. 


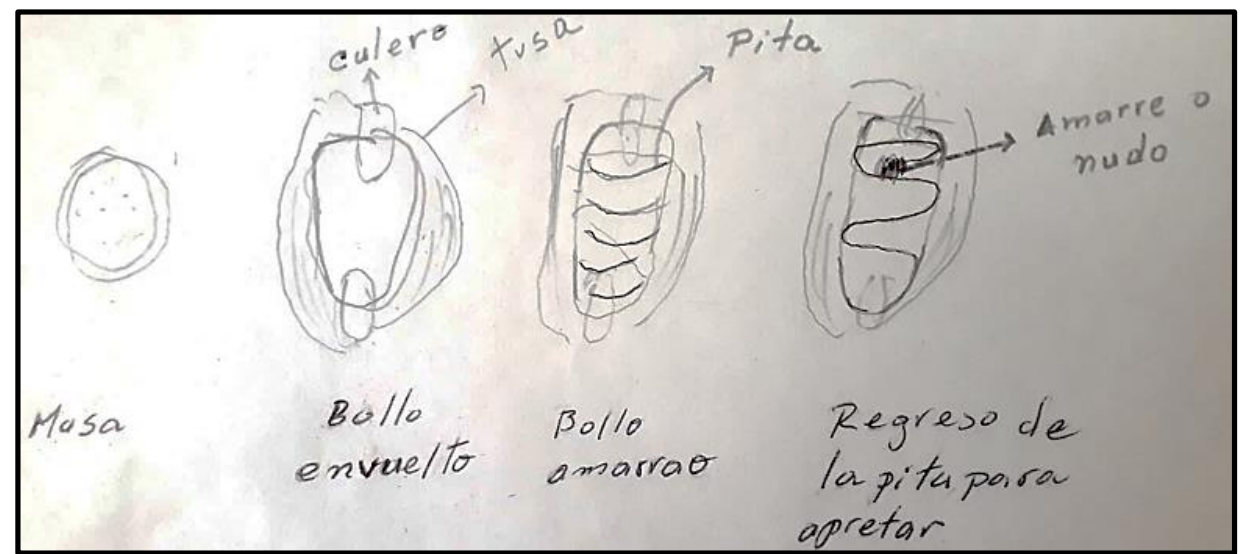

Figura 8. Elementos esenciales para la envoltura y amarre del bollo (dibujo realizado por Jesús).

Fuente. Fotografía de los autores, trabajo de campo.

En la Figura 8, se describen los elementos principales para la envoltura y amarre del bollo, en el que se muestra la posición de los culeros, las tusas que forran la masa, las cinco vueltas de pita, el regreso de la pita y el nudo que el comerciante hace para evitar que se suelte la pita. Jesús menciona que él necesita ayuda de dos personas, su esposa que va peloteando la masa, una ayudante que va envolviendo y él va amarrando el bollo, como se describe el siguiente pasaje de audio.

I. Entonces, ¿Después de la estrujada?

P. Viene la peloteada, empiezan a envolver.

I. El tiempo de envolver...

P. Es el mismo tiempo que se echa uno pa' pelotea, envolviendo y amarrando, de dos a tres horas ahí.

I. O sea, por decir, pelotea que se va haciendo...

P. Bollo que se va envolviendo y amarrado.

I. Se podría decir una peloteada, un bollo... ¿Se utilizan dos personas?

P. Tres personas, aquí somos tres, la que va ahí, la que va envolviendo aquí y yo que voy amarrando allá. Una peloteando, una envolviendo y yo amarrando, ya cuando se acumulan como... que hayan más de ciento cincuenta bollos, ya el tanque, cuando llena el tanque ahí le mete tiempo en candela dos horas, le pongo máximo dos horas.

La acumulación hace referencia a la agrupación de los bollos cuando se van a echar a cocer, como se muestra en la Figura 9. 
Rodríguez, C., Aroca, A. \& Rodríguez, F. M. (2019). Procesos de medición en una práctica artesanal del caribe colombiano. Un estudio desde la Etnomatemática. Revista Latinoamericana de Etnomatemática, 12(4), 41-68. DOI: 10.22267/relatem.19124.36

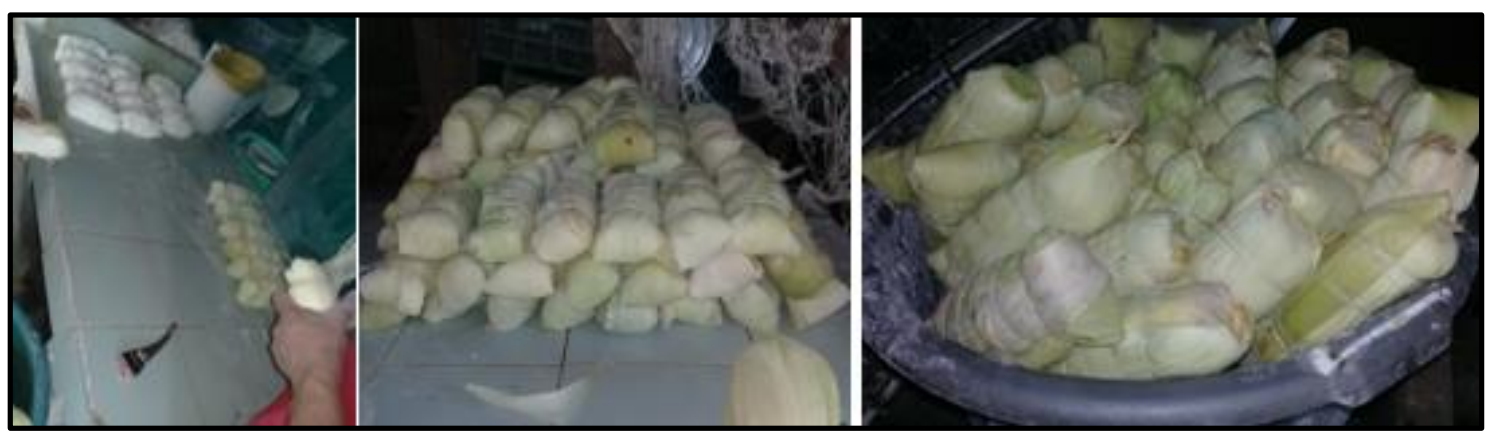

Figura 9. Agrupación de bollos amarrados.

Fuente. Fotografía de los autores, trabajo de campo.

Con la agrupación de los bollos, concluyen los momentos destacados para la elaboración del bollo (pelar, lavar, rallar, exprimir, pelotear, envolver y amarrar), en los que Jesús y sus ayudantes emplean seis horas y media de trabajo por cada carga de yuca, por ejemplo: Pelar $=1$ hora, lavar $=$ media hora, rallar $=1$ hora, exprimir $=1$ hora, pelotear, envolver $\mathrm{y}$ amarrar $=3$ horas.

Para finalizar el proceso de elaboración, se cocina el bollo, lo cual demora dos horas. Para este proceso se utiliza un tanque de aluminio que le caben doscientos bollos y ciento cinco litros de agua, como se describe en el siguiente pasaje de audio y se observa en la Figura 10.

I. ¿Qué tiene en cuenta usted respecto del agua?

P. Medio tanque, este tanque lleno de agua la caben doscientos bollos, entonces uno viene y le pone una tapa aquí, y esto aquí le pongo unas piedras y le pone la tapa grande.

I. Aproximadamente ¿Cuánto de agua le cabe al tanque?

P. Eso si no se, digo yo que se lleva siete baldes de agua, cada balde hace creo quince litros, serían sesenta, ciento y pico e litros.

I. ¿Quince litros cada balde?

P. Cada balde.

I. Y ¿le echa cuántos?

P. Siete baldes, serían treinta, sesenta, noventa, ciento cinco litros, medio tanque.

I. Para doscientos bollos, ya después que se llena se empieza a metele candela y después que hierban, al final destapas cuando se seque y no se despite (Soltar o desamarrar la pita del bollo).

I. Ahí serían doscientos bollos.

P. Que serían doscientas libras.

I. Y ¿Cuántas horas dura?

P. Dos horas. 


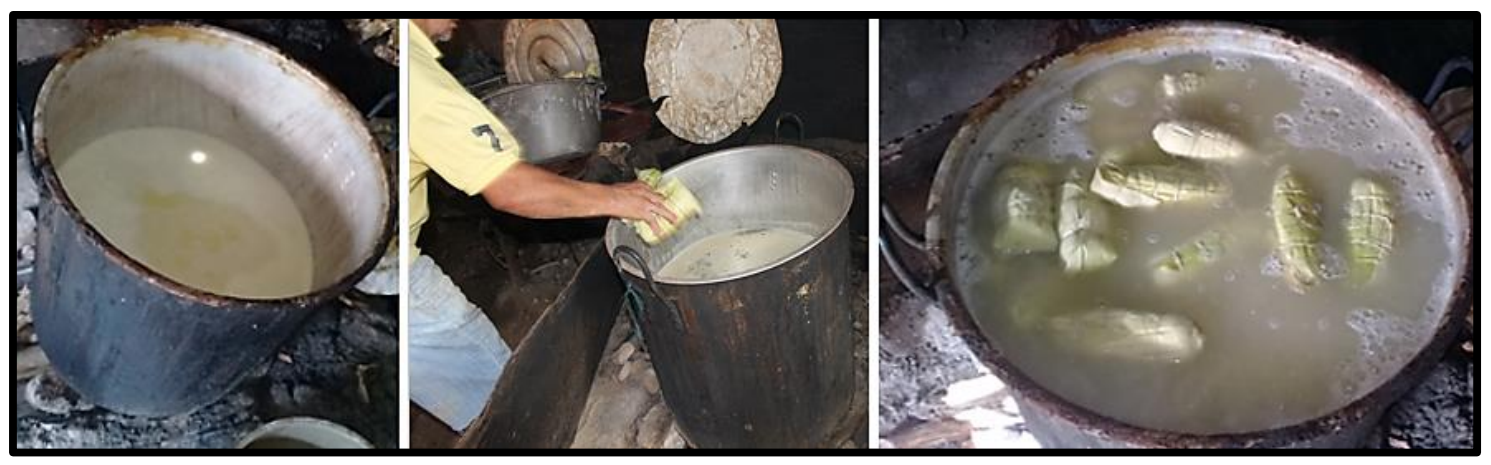

Figura 10. Tanque con agua donde se cocinan los bollos.

Fuente. Fotografía de los autores, trabajo de campo.

Considerando el pasaje de audio anterior, se lograron establecer las siguientes equivalencias entre unidades de medida no convencionales y convencionales (estandarizadas), relacionando el tanque ${ }^{7}$, el balde ${ }^{8}$ y litros:

$$
\begin{gathered}
\frac{1}{2} \text { tanque }=7 \text { baldes de agua } \\
1 \text { balde de agua }=15 \text { litros de agua } \\
\frac{1}{2} \text { tanque de agua }=7 * 15 \text { litros de agua } \\
\frac{1}{2} \text { tanque }=105 \text { litros agua } \\
1 \text { tanque de agua }=14 \text { baldes de agua } \\
1 \text { tanque }=210 \text { litros agua }
\end{gathered}
$$

Otras unidades de medidas no convencionales están relacionadas con la cantidad de bollos y la capacidad del tanque:

$$
\begin{gathered}
1 \text { tanque contiene } 200 \text { bollos } \\
\text { Si } 1 \text { bollo }=1 \text { libra } \\
347 \text { bollos }=347 \text { libras de bollo } \\
200 \text { bollos }=200 \text { libras de bollo } \\
1 \text { tanque contiene } 200 \text { libras de bollos } \\
\text { Si } 1 \text { bollo }=12 \text { onzas } \\
12 \text { onzas }=\frac{3}{4} \text { de una libra } \\
200 \text { bollos }=150 \text { libras } \\
1 \text { tanque contiene } 150 \text { libras de bollos }
\end{gathered}
$$

Respecto del tiempo en la cocinada de los bollos se emplean dos horas: 200 bollos se cocinan en 2 horas. Cabe resaltar que, hasta este momento se han

\footnotetext{
${ }^{7}$ Es el recipiente utilizado para cocinar los bollos. El tanque de agua se refiere a un tanque lleno de agua. ${ }^{8}$ Es el recipiente usado como unidad de medida para medir la cantidad de medio tanque de agua. El balde de agua es el balde lleno de agua.
} 
Rodríguez, C., Aroca, A. \& Rodríguez, F. M. (2019). Procesos de medición en una práctica artesanal del caribe colombiano. Un estudio desde la Etnomatemática. Revista Latinoamericana de Etnomatemática, 12(4), 41-68. DOI: 10.22267/relatem.19124.36

empleado ocho horas y media. Preparación del bollo 6:30 horas más 2 horas cocinándose. Asimismo, para cocinar los bollos se lleva una carga de leña si los palos son delgados y si la leña es gruesa se lleva un lao de leña (bulto de leña). La leña puede ser del árbol de aromo (Acacia farnesiana) o matarratón (Gliricidia sepium), debido a que el fuego es más consistente y humea poco.

En la forma de medir la leña se pueden expresar equivalencias entre unidades de medidas. Se obtuvo información acerca de algunas equivalencias entre unidades de medidas no convencionales utilizadas por Jesús. Cuando los palos de leña son gruesos (caso 1) se dan las siguientes equivalencias:

1 carga de leña $=2$ laos o bultos de leña.

1 lao de leña $=30$ palos de leña.

1 carga de leña $=60$ palos de leña.

2 laos o bultos de leñ $a=60$ palos de leña.

Cuando los palos de leña son delgados (caso 2), Jesús tiene en cuenta la siguiente información:

1 carga de leñ $a=2$ laos o bultos de leña.

1 lao de leña $=35$ palos de leña.

1 carga de leñ $a=70$ palos de leñ.

2 laos o bultos de leñ $a=70$ palos de leñ $a$.

Para los dos casos evidenciados anteriormente, se puede utilizar la expresión: $\frac{1}{2}$ carga de leñ $a=1$ lao de leña (bulto).

En el corregimiento de Sibarco, se pueden utilizar diferentes términos para refiriese a un bulto, por ejemplo: 1 bulto $=1$ saco $=1$ lao $=1$ tercio. Los términos más utilizados son bulto y saco por motivos comerciales. Sin embargo, para los términos lao y tercio se tiene una distinción respecto a la capacidad de carga del burro, es decir, 1 lao o tercio hace referencia a lo que se puede cargar en el costado del burro. El término tercio, se deriva de una palabra utilizada por el antiguo campesino Sibarquero ${ }^{9}$, quien podría referirse libremente a dos tercios de yuca que significa dos sacos, dos bultos o dos laos de yuca. En este sentido, en la actualidad se podrían encontrar personas adultas y jóvenes que se refieran a un tercio.

$$
\text { Un tercio de yuca }=1 \text { lao de yuca. }
$$

\footnotetext{
${ }^{9}$ Gentilicio de la persona originaria del corregimiento de Sibarco.
} 
Un tercio de leñ $a=1$ bulto de leña.

Dos tercios de yuca $=2$ laos de yuca.

Dos tercios de yuca $=1$ carga de yuca.

Si hacemos una relación paralela y comparativa con los términos empleados en esta práctica de la elaboración de bollos de yuca con el símbolo de la matemática escolar que hace referencia a cuando dos expresiones son diferentes, $\neq$, entonces se llegan a aparentes contradicciones entre lenguaje local y representación simbólica escolar, por ejemplo:

$$
\begin{gathered}
\text { Un tercio de yuca } \neq \frac{1}{3} \text { del bulto o saco de yuca. } \\
\text { Un tercio de leña } \neq \frac{1}{3} \text { del bulto de leña. } \\
\text { Dos tercios de yuca } \neq \frac{2}{3} \text { de la carga de yuca. }
\end{gathered}
$$

Además, en Sibarco un tercio de yuca no hace referencia a dividir una yuca (un todo) en tres partes iguales y tomar una parte, un tercio, $\left(\frac{1}{3}\right)$, del todo, o bien, tomar una tercera parte de la cantidad de yuca de un bulto (todo), sino, que la terminología usada se asocia a lo que pude cargar un burro en su costado, es decir, un tercio es igual a un bulto completo.

Luego que los bollos se hayan escurrido después de la cocinada, Jesús los lleva al mercado para ser comercializados. Para la venta de los bollos se tienen dos tipos de precios, uno para abastecer a las tiendas, cada bollo cuesta $\$ 800$ para ser vendidos a $\$ 1.000$, y el otro de \$1.000, denominado precio estándar en la venta de Jesús, ya sea en Sibarco o en el mercado de Baranoa. De esta información, se deducen las siguientes equivalencias: 1 bollo $=\$ 1.000$, como precio estándar y 1 bollo $=\$ 800$, como precio de tienda . En la forma de partir el bollo se evidencian unas rodajas o rebanadas como se observa en la Figura 11, por ejemplo: 1 bollo $=7$ rodajas delgadas $y 1$ bollo $=$ 6 rodajas gruesas. 
Rodríguez, C., Aroca, A. \& Rodríguez, F. M. (2019). Procesos de medición en una práctica artesanal del caribe colombiano. Un estudio desde la Etnomatemática. Revista Latinoamericana de Etnomatemática, 12(4), 41-68. DOI: 10.22267/relatem.19124.36

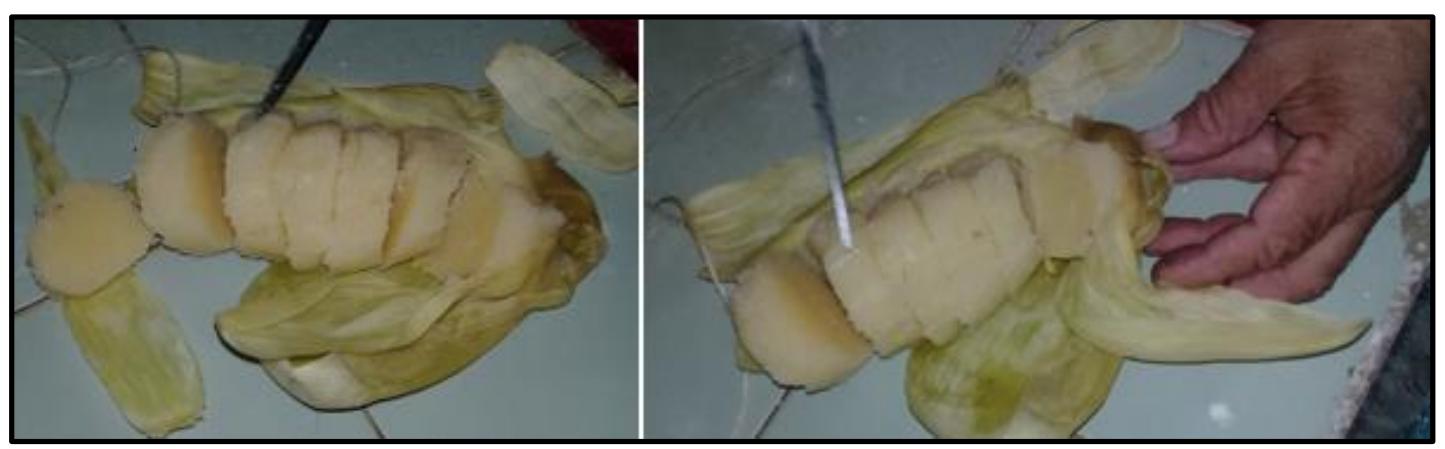

Figura 1. Partición del bollo de yuca, 6 o 7 rodajas.

Fuente. Fotografía de los autores, trabajo de campo.

Cuando Jesús lleva los bollos al mercado los empaca en un saco que le caben a lo más cien bollos, es decir, pesa cien libras si cada unidad pesa una libra y si cada unidad pesa doce onzas, cada saco pesa setenta y cinco libras, como se expresa a continuación:

$$
\begin{gathered}
\text { Un saco contiene cien bollos } \\
\text { Si un bollo }=1 \text { libra } \\
\text { Un saco }=100 \text { libras de bollo } \\
\text { Si un bollo }=12 \text { onzas } \\
\text { Un saco }=75 \text { libras de bollo }
\end{gathered}
$$

De forma general, de las unidades de medidas mostradas se logró establecer una clasificación entre las diferentes unidades de medidas de longitud, capacidad, masa y tiempo y su utilidad en cada momento de la elaboración de los bollos, como se muestra en la Tabla 3. 


\begin{tabular}{|c|c|c|c|c|}
\hline Momentos & Unidades & le medida & & \\
\hline $\begin{array}{l}\text { de la } \\
\text { elaboración } \\
\text { del bollo }\end{array}$ & Convencional & $\begin{array}{l}\text { No } \\
\text { convencional }\end{array}$ & Magnitud & Equivalencias y conversiones \\
\hline \multirow{2}{*}{$\begin{array}{l}\text { Arrancar y } \\
\text { empacar la } \\
\quad \text { yuca }\end{array}$} & Libra & & Masa & $\begin{array}{c}1 \text { carga de yuca }=2 \text { sacos de yuca. } \\
1 \text { bulto de yuca }=1 \text { saco de yuca. } \\
1 \text { carga de yuca }=2 \text { bultos o sacos de yuca. }\end{array}$ \\
\hline & & $\begin{array}{l}\text { Bulto, saco, } \\
\text { lao, tercio y } \\
\quad \text { carga }\end{array}$ & Capacidad & $\begin{array}{c}\frac{1}{2} \text { carga de yuca = } 1 \text { saco o bulto de yuca. } \\
1 \text { bulto o saco de yuca }=120 \text { libras. }\end{array}$ \\
\hline Pelar la yuca. & Hora & & Tiempo & $\frac{1}{1}$ caraa de vuca $=120$ libras entonces 1 carag de vuca $=240$ libras \\
\hline Rallar la yuca & Hora & Saco & $\begin{array}{l}\text { Tiempo } \\
\text { Capacidad }\end{array}$ & 1 braza $\cong 2$ metros, entonces $\frac{1}{2}$ braza $\cong 1$ metro. \\
\hline $\begin{array}{l}\text { Escurrir la } \\
\text { masa }\end{array}$ & Hora & & Tiempo & $\frac{1}{2}$ tanque $=7$ baldes de agua \\
\hline \multirow{3}{*}{$\begin{array}{l}\text { Pelotear, } \\
\text { forrar y } \\
\text { amarar la } \\
\text { masa }\end{array}$} & Libra y onza & & Masa & $\begin{array}{c}1 \text { balde de agua }=15 \text { litros de agua, entonces } \frac{1}{2} \text { tanque }= \\
105 \text { litros agua. }\end{array}$ \\
\hline & Metro & Braza & Longitud & $\begin{array}{c}1 \text { tanque de agua }=14 \text { baldes de agua, entonces } 1 \text { tanque }= \\
210 \text { litros agua. }\end{array}$ \\
\hline & Litro & & Capacidad & 1 tanque contiene 200 bollos. \\
\hline \multirow[t]{5}{*}{$\begin{array}{l}\text { Cocinar el } \\
\text { bollo }\end{array}$} & & $\begin{array}{l}\text { Tanque y } \\
\text { balde }\end{array}$ & Capacidad & $\begin{array}{c}\text { Si } 1 \text { bollo }=1 \text { libra, entonces } 200 \text { bollos }=200 \text { libras. } \\
1 \text { tanque contiene } 200 \text { libras de bollos. }\end{array}$ \\
\hline & Hora & & Tiempo & 1 bollo $=12$ onzas. \\
\hline & & & & 12 onzas $=\frac{3}{4}$ de libra, entonces 200 bollos $=150$ libras \\
\hline & Libra & & Masa & $\begin{array}{l}1 \text { tanque contiene } 150 \text { libras de bollos. } \\
1 \text { carga de leñ } a=2 \text { laos o bultos de leña. }\end{array}$ \\
\hline & & Saco o bulto & Capacidad & $\begin{array}{l}1 \text { lao de leña = } 30 \text { palos de leña, entonces } 1 \text { carga de leña } a \\
60 \text { palos de leña. } \\
2 \text { laos o bultos de leña } a=60 \text { palos de leña. }\end{array}$ \\
\hline
\end{tabular}




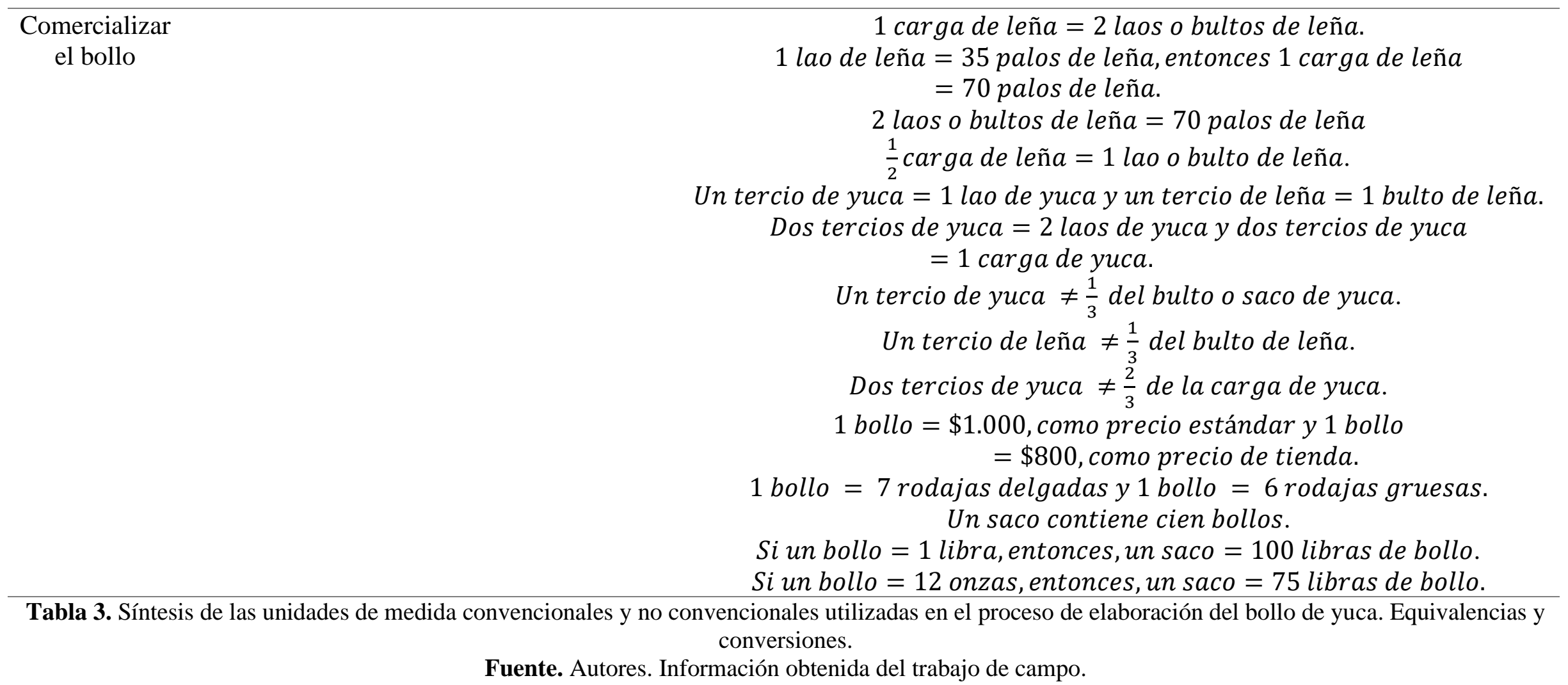




\section{DISCUSIÓN Y CONCLUSIONES}

Los hallazgos de esta investigación permiten evidenciar las diferentes formas de medir de un comerciante de bollos de yuca del corregimiento de Sibarco. En esta práctica artesanal, se reconocen trece tipos de unidades de medidas mencionadas en la Tabla 3, con las cuales se establecieron equivalencias y las posibles conversiones entre una misma unidad y entre unidades diferentes, las cuales son consideradas un factor importante como lo menciona el MEN (2006) para el desarrollo del pensamiento métrico y los sistemas métricos o de medidas. En este sentido, referirse a una carga, implícitamente están los bultos, sacos, tercios y respecto del peso de la yuca contenida en los sacos viene dado en libras y cada unidad de bollo se mide por libra u onza. También, al hacer referencia al tanque, se tienen en cuenta los baldes y la respectiva capacidad en litros, y en todo el proceso descriptivo se dio a conocer el tiempo empleado en la elaboración de los bollos dado en horas.

Al estudiar la práctica del comerciante Jesús, se logró identificar que algunas unidades de medidas no convencionales han sido reportadas en otras investigaciones (Berrio, 2009; Chieus, 2009; Arias et al., 2010; Rey y Aroca, 2011; Aroca, 2008; 2012; Carabalí, 2012; Zambrano, 2012; Ávila, 2014; Oliveira Júnior y Mendes dos Santos, 2016; RodríguezNieto et al., 2017; Rodríguez-Nieto et al., 2019), pero en la práctica de elaboración del bollo de yuca se usan de forma diferente y presentan otras características, entre las que se destacan las equivalencias y conversiones, que pueden enriquecer el lenguaje matemático en términos cotidianos, por ejemplo, al referirse a "un tercio igual a un bulto". Esto sucede porque cada pueblo tiene una cultura diferente y desarrolla su propia matemática (Gerdes, 2013).

Cabe destacar que, en esta investigación solo se entrevistó a un comerciante quien mencionó que, la elaboración del bollo de yuca es similar en todas las fábricas de Sibarco, pero sugerimos ampliar la investigación con otra población de la región caribe colombiana para explorar otras características e incluso otras formas de medir, o bien, identificar otras actividades universales como se proponen en Bishop (1999).

Se pretende que estos resultados puedan ser conocidos por los profesores de matemáticas para que diseñen tareas contextualizadas y puedan utilizarse para problematizar los resultados con los estudiantes en el salón de clases de las instituciones educativas, cuyo contexto escolar reconozca esta práctica en su comunidad. La problematización estaría en función de las unidades de medidas, longitudes, equivalencias, conversiones, relaciones entre sí, entre otros temas que mostraría la postura didáctica del programa 
Rodríguez, C., Aroca, A. \& Rodríguez, F. M. (2019). Procesos de medición en una práctica artesanal del caribe colombiano. Un estudio desde la Etnomatemática. Revista Latinoamericana de Etnomatemática, 12(4), 41-68. DOI: 10.22267/relatem.19124.36

Etnomatemática (Aroca, 2018). Una vez más se hace énfasis que las matemáticas son una construcción cultural, que producen, desarrollan, comparten los pueblos y no sólo son producto de los textos escolares.

\section{AGRADECIMIENTOS}

Agradecemos al comerciante Jesús, a su familia y a su grupo de trabajo por suministrarnos la información acerca de la elaboración del bollo de yuca. A Idamis, Ana M., Ramiro, María, Hilton, Belkys, Julitsha y Yadira por posibilitar la comunicación con el comerciante.

\section{Conflicto de intereses}

La información proporcionada en este artículo no tiene conflictos de intereses.

\section{REFERENCIAS}

Álvarez, B., Denise De Paula, C., \& Durango, A. (2016). Caracterización del bollo limpio de maíz producido en el Bajo Sinú del departamento de Córdoba. Agronomía colombiana, 34(1Supl.), 1252-1254.

Alsina, Á. y Salgado, M. (2019). Descubriendo la medida en un contexto de interacción, negociación y diálogo: Un estudio de caso en Educación Infantil, PNA, 14(1), 121.

Ameigeiras, A. R. (2006). El abordaje etnográfico en la investigación social. En I. Vasilachis de Gialdino. (Ed.), Estrategias cualitativas de investigación (pp. 107151). Buenos Aires: Gedisa.

Aravena, L., Loncomilla, A., \& Pizarro, D. (2020). Nociones matemáticas en la construcción de muebles. Estudio de caso con un mueblista del sur de Chile. Tesis de pregrado. Universidad Austral de Chile, Puerto Montt.

Arias, P. E., Morales, R. F., \& Orjuela, J.I. (2010). Etnomatemática y la construcción civil. Revista Latinoamericana de Etnomatemática, 3(1), 4-30.

Aroca, A. (2008). Análisis a una Figura Tradicional de las Mochilas Arhuacas. Comunidad Indígena Arhuaca. Sierra Nevada de Santa Marta, Colombia. Boletim de Educação Matemática, 21 (30).

Aroca, A. (2012). Las formas de orientación espacial de los pescadores de Buenaventura, Colombia. Revista U.D.C.A Actualidad \& Divulgación Científica, 15(2), 457 465.

Aroca, A. (2013). Análisis de los diseños en los hipogeos del parque arqueológico de Tierradentro, Cauca, Colombia. Rev. U.D.C.A Act. \& Div. Cient., 16(2), 525-534.

Aroca, A. (2016). La definición etimológica de Etnomatemática e implicaciones en Educación Matemática. Educación matemática, 28(2), 175-195. 
Aroca, A. (2018a). Aprendizaje paralelo y comparativo: la postura didáctica del programa Etnomatemática. Revista Latinoamericana de Etnomatemática, 11(2), 4-7.

Aroca, A. (2018b). Etnografía del saber matemático de pescadores de Buenaventura. Pacífico colombiano. Elementos para una educación matemática contextualizada. Barranquilla: Editorial Universidad del Atlántico.

Ávila, A. (2014). La Etnomatemática en la educación indígena: así se concibe, así se pone en práctica. Revista Latinoamericana de Etnomatemática, 7(1), 19-49.

Berrio, L. (2009). "La Medida" en un contexto de escuela Indígena: El caso del pueblo Tule y el caso del pueblo Embera-Chamí. Tesis de Pregrado, Universida de Antioquia, Medellín.

Bishop, A. (1999). Enculturación matemática. La educación matemática desde una perspectiva cultural. Barcelona: Paidós.

Blanco-Álvarez, H., Fernández-Oliveras, A., \& Oliveras, M. (2017). Medidas de capacidad volumétrica no convencionales: aportes a la educación primaria. Enseñanza de las ciencias: revista de investigación y experiencias didácticas, (Extra), 2071-2078.

Carabalí, J. (2012). Patrones de Medidas no Convencionales: El caso de la longitud en el barrio Desepaz del municipio de Santiago de Cali, Colombia. Tesis de Pregrado, Universidad del Valle, Santiago de Cali.

Chieus, G. (2009). A Braça da Rede, uma Técnica Caiçara de Medir. Revista Latinoamericana de Etnomatemática, 2(2), 4-17.

D’Ambrosio, U. (2014). Las bases conceptuales del Programa Etnomatemática. Revista Latinoamericana de Etnomatemática, 7(2), 100-107.

D'Ambrosio, U. (2016). Polysemic Interactions between Ethnomathematics and Culturally Relevant Pedagogy. In M. Rosa, U. D’Ambrosio, D. C. Orey, L. Shirley, W. V. Alangui, P. Palhares, \& M. E. Gavarrete (Eds.), An Overview of the History of Ethnomathematics (pp. 5-10). Springer International Publishing.

D’Ambrosio, U., \& Knijnik, G. (2020). Encyclopedia of Mathematics Education. In S. Lerman (Ed.), Ethnomathematics (pp. 283-288). Springer Nature Switzerland AG.

Dickson, L., Brown, M., \& Gibson, O. (1991). El aprendizaje de las matemáticas. Madrid: MEC y Labor.

Enríquez, W., Millán, B., \& Aroca, A. (2012). Análisis a los diseños de los sombreros de iraca elaborados en colón - Génova, Nariño. Rev. U.D.C.A Act. \& Div. Cient., 15(1), $227-237$.

García-García, J., \& Bernandino-Silverio, N. (2019). Conocimientos geométricos en la elaboración de un artefacto en una comunidad Ñuu savi. IE Revista de Investigación Educativa de la REDIECH, 10(19), 105-120.

Goetz, J., \& LeCompte, D. (1988). Etnografía y Diseño Cualitativo en investigación educativa. Madrid: Editorial Morata S.A.

Gerdes, P. (2013). Geometría y Cestería de los Bora en la Amazonía Peruana. Lima: Ministerio de Educación.

Godino, J. D., Batanero, C., \& Roa, R. (2002). Medida de magnitudes y su didáctica para maestros. Universidad de Granada, Departamento de Didáctica de la Matemática. 
Rodríguez, C., Aroca, A. \& Rodríguez, F. M. (2019). Procesos de medición en una práctica artesanal del caribe colombiano. Un estudio desde la Etnomatemática. Revista Latinoamericana de Etnomatemática, 12(4), 41-68. DOI: 10.22267/relatem.19124.36

Hernández, R., Fernández, C., \& Baptista, P. (2014). Metodología de la investigación. México: Mc Graw Hill.

Knowles, M., Pabón, M., \& Carulla, J. (2012). Uso de la yuca (Manihot esculenta Crantz) y otras fuentes de almidones no convencionales en la alimentación de rumiantes. Revista Colombiana de Ciencias Pecuarias, 25 (3), 488-499.

Kula, W. (1980). Las Medidas y los Hombres (3a Edición ed.). Madrid: Siglo XXI de España Editores.

Mera, I., \& Carrera, J. (2005). Obtención de glucosa a partir de almidón de yuca Manihot sculenta. Facultad de Ciencias Agropecuarias, 3(1), 54-63.

Meza, Y., \& Julca, A. (2015). Sustentabilidad de los sistemas de cultivo con yuca (Manihot esculenta Crantz) en la subcuenca de Santa Teresa, Cusco. Ecología Aplicada, 14(1), 55-63.

Ministerio de Educación Nacional [MEN]. (2006). Estándares básicos de competencias en lenguaje, Matemáticas, ciencia y ciudadanas. Bogotá, Colombia: MEN.

Mosquera, G., Rodríguez-Nieto, C. y Suárez, S. (2015). Dos sistemas de medidas no convencionales en la pesca artesanal con cometas en bocas de ceniza y su potencial para la educación matemática. Tesis de pregrado, Universidad del Atlántico, Barranquilla-Colombia.

Oliveira Júnior, B., \& Mendes dos Santos, E. (2016). Etnomatemática: O ensino de medida de comprimento no $6^{\circ}$ ano do ensino fundamental na Escola Indígena Kanamari Maraã-AM, Brasil. Revista Latinoamericana de Etnomatemática, 9(2), 53-66.

Real Academia Española. (2018). Diccionario de la lengua española. Madrid, España: Autor.

Rey, M., \& Aroca, A. (2011). Medición y estimación de los albañiles, un aporte a la educación Matemática. Revista U.D.C.A Actualidad \& Divulgación Científica, 14 (1), 137-147.

Rodríguez-Nieto, C., Morales, L., Muñoz, A., \& Navarro, C. (2017). Medidas no convencionales: El caso del mercado Baltazar R. Leyva Mancilla, Chilpancingo, Gro. En Federación Española de Sociedades de Profesores de Matemáticas (Eds.), VIII Congreso Iberoamericano de Educación Matemática, (pp. 225-233). Madrid, España.

Rodríguez-Nieto, C., Mosquera, G., \& Aroca, A. (2019). Dos sistemas de medidas no convencionales en la pesca artesanal con cometa en Bocas de Cenizas. Revista Latinoamericana de Etnomatemática, 12(1), 6-24.

Rosa, M., \& Shirley, L. (2016). Polysemic Interactions between Ethnomathematics and Culturally Relevant Pedagogy. In M. Rosa, U. D’Ambrosio, D. C. Orey, L. Shirley, W. V. Alangui, P. Palhares, \& M. E. Gavarrete (Eds.), Introduction (pp. 1-3). Springer International Publishing.

Rosa, M., \& Orey, D. (2018). Propondo um currículo trívium fundamentado nas perspectivas da Etnomatemática e da modelagem. Revista educação matemática en foco, 7(2), 63-98.

Sandoval, C. (2002). Investigación cualitativa. Bogotá: ARFO Editores e impresiones Ltda. 
São Paulo [State]. (2012). Currículo do Estado de São Paulo: matemática e suas tecnologias. Secretaria da Educação, São Paulo, Brasil.

Shirley, L. y Palhares, P. (2016). Polysemic Interactions between Ethnomathematics and Culturally Relevant Pedagogy. In M. Rosa, U. D’Ambrosio, D. C. Orey, L. Shirley, W. V. Alangui, P. Palhares, \& M. E. Gavarrete (Eds.), Ethnomathematics and its Diverse Pedagogical Approaches (pp. 13-17). Springer International Publishing.

Soza, M., \& Dávila, A. (2012). Etno-matemática en indígenas Ulwas, comunidad de Karawala, Región Autónoma Atlántico Sur, Nicaragua. Ciencia e interculturalidad, 11(2), 70-87.

Spradley, J. (1979). The Ethnographic Interview. Nueva York: Holt, Rinehart and Winston.

Suárez, L., \& Mederos, V. (2011). Apuntes sobre el cultivo de la yucca (Manihot esculenta Crantz). Tendencias actuales. Cultivos Tropicales, 32(3), 27-35.

Trujillo, O., Miranda, I. \& De la Hoz, E. (2018). Los sistemas de medida en la comunidad Arhuaca: su uso en distintos contextos. Revista Latinoamericana de Etnomatemática, 11(2), 31-51.

Vasilachis De Gialdino, I. (2006) "La investigación cualitativa". En I. Vasilachis de Gialdino. (Ed.), Estrategias cualitativas de investigación (pp. 23-60). Buenos Aires: Gedisa.

Vega, Y., Huguet, S. y Peralta, S. (2015). Propuesta de mejoramiento de un producto en la ciudad de Barranquilla: bollo de maíz ejecutivo. Liderazgo y Estrategias, 5(1), $36-47$.

VIM. (2012). Vocabulario Internacional de Metrología Conceptos fundamentales y generales, y términos asociados VIM (3ra edición en español). Madrid: Centro Español de Metrología.

Zambrano, J. A. (2012). Prácticas matemáticas en una plaza de mercado. Revista Latinoamericana de Etnomatemática, 5(1), 35-61. 